\title{
Fifty years of research in African demography: progresses and challenges
}

\author{
Michel Garenne \\ - Institut de Recherche pour le Développement (IRD), France \\ Witwatersrand University, School of Public Health, South Africa \\ - Institut Pasteur, Unité d'épidémiologie des maladies émergentes, \\ 25 rue du Docteur Roux, 75015, Paris, France \\ Phone : +33-1-40-61-39-58; Fax : +33-1-45-68-88-76 \\ Michel.Garenne@pasteur.fr
}

\section{Abstract}

The paper presents and discusses the progress in knowledge of African populations and their dynamics over the past 50 years. It takes as a starting point the landmark series of studies published in The Demography of Tropical Africa. Since then major progresses in data collection and data analysis were made, which are reviewed and discussed, with special reference to direct and indirect methods of demographic estimation. A major change occurred about 25 years ago with the development of DHS surveys and the focus on epidemiology and public health issues. Demographic research had to change its paradigms, and major advances were made in our understanding of population dynamics in relation with health issues. In a last part, the paper addresses special topics, unforeseeable events such as the HIV/AIDS epidemics which had major consequences for many demographic processes, and new fields for research around environmental issues.

Key Words: Demography; public health; demographic methods; history, sub-Saharan Africa

\section{Résumé en français}

Cette communication présente et discute les progrès faits depuis un demi-siècle sur la connaissance des populations africaines et leurs dynamiques. Elle part d'une série d'études pionnières publiées dans l'ouvrage intitulé : The Demography of Tropical Africa. Depuis cette époque, de nombreux progrès ont été faits en matière de collecte et d'analyse des données, qui sont présentés et discutés, en mettant l'accent sur les méthodes directes et indirectes d'estimation démographique. Un changement majeur se produit 25 ans plus tard avec le développement des enquêtes démographiques et sanitaires (EDS), l'intérêt se portant alors sur les questions épidémiologiques et de santé publique. La recherche démographique a dû changer ses paradigmes, permettant de réaliser des avancées majeures sur la compréhension des dynamiques de population en relation avec les questions de santé. Dans une dernière partie, la communication traite de sujets

I. Paper prepared for the $25^{\text {th }}$ anniversary of African Population Studies. 
spéciaux, d'évènements imprévisibles comme l'émergence du VIH/sida, qui a eu d'énormes conséquences sur les phénomènes démographiques, et de nouvelles questions comme celles qui ont trait aux questions d'environnement.

Mots clé: Démographie; Santé publique; Méthodes d'estimation; Histoire; Afrique sub-Saharienne.

\section{Introduction}

Just 50 years ago, in 1961, two books were published summarizing what was known about the demography of tropical Africa (Galeoti, 196I; Lorimer, 1961). The first one is now largely ignored and rarely cited. Lorimer's book was very influential as it started the adventure leading seven years later to the publication of "The Demography of Tropical Africa", a collection of articles that have been the origin of research on African demography (Brass et al. 1968). A first seminar on African demography was held in Paris in 1959 by Lorimer, followed in the 1960s and early 1970s by others in lbadan, Nairobi and Accra (Caldwell and Okonjo, 1968, Ominde and Ejiogu, 1972, Cantrelle, 1974). These were followed by a long series of meetings, seminars and conferences on African Demography, the last of which being the $6^{\text {th }}$ UAPS conference to be held in Ouagadougou, Burkina Faso in December 201I. Another landmark is the creation of the Union for African Population Studies (UAPS/UEPA) in 1984.

This paper provides a personal view on the development of African demography over this 50 -year period. It conveniently divides this time frame into two periods of about 25 years each. These two periods are arbitrary, and correspond to the creation of this Journal (African Population studies) in 1986, just two years after the development of
DHS surveys, an event which has changed dramatically our level of knowledge and understanding of African populations and their dynamics. In this contribution to the $25^{\text {th }}$ anniversary of African Population Studies, the author would like to share a few ideas and facts dealing with his own experience with African demography. Ironically, the author received his training in demography at the end of the first period (19781982), in France and in the United States, with the main focus on issues specific to this period which are detailed below, and primarily data collection and demographic estimation techniques. But most of his research work has been conducted during the second period, with totally different paradigms, and the need to conduct research on different topics with different tools and with a multidisciplinary approach.

The colonial period (1880-1960)

During the colonial period the focus was on getting cheap labour to provide the work force for development projects: basic infrastructure and communications (towns, roads, railways), mines and quarries, and estates producing agricultural export goods (sugar cane, peanuts, cocoa, coffee, tea, palm oil, rubber, etc.). So, the main concern for managing the colonial economy was with the number of people and their geographical distribution. The focus was therefore on administrative cen- 
suses which were conducted on a routine basis (every year or every five years) in most areas under colonial control (Cordell and Gregory, 1980).

In terms of issues, the main concern was with low population density and tropical diseases, which were seen as considerable limitations to economic development. Efforts were made to understand and reduce infertility, and large programs were developed to control infectious and parasitic diseases, such as malaria, sleeping sickness (trypanosomiasis), yellow fever, yaws, syphilis, shistosomiasis, as well as tuberculosis, leprosy and smallpox (Bado, 2005; Retel-Laurentin, 1974).

The first modern censuses were conducted at the end of the colonial period and the first demographic sample surveys seem to be that conducted in 1948 in Southern Rhodesia, now Zimbabwe, among the Anglophone countries, and that conducted in 1954 in Guinea among the Francophone countries (Shaul and Myburgh, 1950; Gendreau, 1993).

\section{Part 1 - The first quarter of a century in post-colonial times (1961-1985)}

The crucial period of the early 1960s was the time of the end of the colonial period in most African countries, and the beginning of the new era of building modern independent states. The needs for demographic and health information systems became different, as they were required for building a modern administration. For demographers, the focus was on getting accurate data on population size and structures, and on basic demographic dynamics (fertility, mortality, nuptiality, migration, urbanization, labour force). The concerns shifted towards rapid population growth, changing levels of mortality, rapid urbanization, and major migration movements. For demographic research, the focus was on measurement tools and the development of appropriate data collection methods because vital registration was deficient. Later, a series of research focused on the impact of family planning programs which had started in the 1960s and 1970s.

The Niakhar surveys (1963-1982)

A good example of this concern for data collection was the demographic surveillance system (DSS) started in 1963 by Pierre Cantrelle in Senegal. In this original enterprise, two sites were originally set up: Niakhar and PaosKoto, which had been selected because the first one was an area with high population density and net out-migration, and the second an area of low population density and net in-migration. The focus of the research was on proper measurement of basic demographic rates of fertility, mortality, migration and nuptiality, all parameters which were simply not available at that time. The data collection technique was simple: a comprehensive census with some retrospective information on mortality and fertility, and yearly rounds updating the population file by recording births, deaths, in-and out-migration and changes in marital status (marriages, divorces, separations) that occurred since the previous round, realizing a full scale population register on a small population. More information was collected, such as causes of death, reasons for migration, breastfeeding and weaning status, measles and measles vaccination. The first series of rounds lasted five 
years, and the sample was later reduced to smaller size, and continued until 1982 on the same model. The outcome was very successful, and showed that with simple means and appropriate interview techniques and questionnaires, reliable information could be gathered at low cost. Detailed research was conducted on the intermediate variables of natural fertility, as well as on the age pattern of mortality (Cantrelle, 1969; Cantrelle \& Leridon, 1971; Garenne \& Cantrelle 1989, 1991).

Years later, it became obvious that measurement was no longer an issue, and that more data were needed than basic demographic events if one wanted to better understand the complex demographic processes underway. The site is still running, and has hosted major studies of worldwide scope, such as a study on the relationship between nutritional status and mortality, vaccine trials, various studies on malaria and other diseases, and numerous studies in all fields of social sciences (Garenne et al., I99I; Garenne et al., 2000; Lericollais et al. 1997 ; Niakhar web site).

INSEE surveys, and other demographic surveys

As part of an effort to set up a new administration in independent states, the French National Institute of Statistics (INSEE) organized a series of Demographic Sample Surveys in many francophone countries, starting with Guinea in 1954-1955 (GDA, 197I; Gendreau, 1977; 1993). Similar surveys were conducted in countries under Belgian colonial administration, in particular the famous 1955-1957 survey in Congo (Romaniuk, 196I). A similar survey was conducted in Sudan (1955-1956). Here again the focus was on measurement of basic demographic parameters. These surveys were based on fairly large samples (typical size was some 30,000 households). They were of good quality, and produced reliable data on fertility rates, mortality rates, age structures and numerous other indicators. The first life tables were calculated, which were used later to produce model life tables (Clairin et al., 1980). Some of the original data still exist, and might be eventually deposited at IPUMS.

Another major advance in the 1970s was the development of the World Fertility Survey (WFS), the aim of which was to produce reliable data on fertility and family planning, and which also produced data on child mortality and various contextual variables. For sub-Saharan Africa, the WFS surveys had serious limitations: they covered only ten countries, had limited scope, and they were based on tiny samples which hampered detailed statistical analysis.

\section{Censuses}

Modern censuses, with detailed individual information (age, sex, marital status, education, occupation, housing etc.) were conducted already at the end of the colonial period, in the British colonies of East Africa (since 1948), in the Portuguese colonies (since 1940), and later in the French and Belgian colonies. The quality of the data was mixed. Major problems were detected with inaccurate information, in particular age, and with missing values. These early censuses were often poorly analyzed, as researchers had no access to original data. However, they produced estimates of fertility and child mortality for numerous countries, and were used extensively for the first synthesis of mor- 
tality trends in Africa (Hill, 1991; Feachem and Jamison, 1991).

Much has been learned since, and the quality of census data improved over time. However, some basic problems noted in the early censuses, such as large numbers of missing values for the number of children ever born among young women, which led to the development of a correction method by El Badry (196I), still existed in the 200 I census of South Africa. The censuses have been the main source of population reconstruction and projections by international and specialized agencies, such as the United Nations Population Division, and the US Census Bureau.

The contribution of the

"Demography of Tropical Africa"

The work synthesized in the "Demography of Tropical Africa" focused on data availability, data quality, and adjustment of poor quality data. The studies covered most of what is now called "subSaharan Africa", starting from the Sahelian band going from Mauritania to Sudan in the North to Southern Rhodesia and Mozambique in the South, while ignoring the Southern cone (South Africa, Namibia, Botswana) and Madagascar, as well as Ethiopia and Somalia in the East. Some countries were also not covered because of a lack of data (Chad, Sierra Leone), as was the case for the African Islands. Nevertheless, the study was fairly comprehensive and produced estimates of fertility, mortality and nuptiality for most countries considered. Data quality was seen as a major problem, and a full chapter is devoted to this issue, in particular to reporting births and deaths in censuses and retrospective surveys, and to age misreporting.
Special attention was also devoted to sex ratios at birth, sex ratios in the population, and biases associated with age of respondent. Various techniques of adjustment were developed. The most striking example of data quality and adjustment is probably the correction of $+40 \%$ for under-five mortality in Mozambique. This study was also the beginning of the adventure of indirect methods of demographic estimation, namely the P/F ratio method correcting for possible under-estimation of fertility and the Brass method converting the proportion of children dead to women of a given age group into life table estimates. These were followed by numerous other indirect methods (see below).

\section{Part II: The second quarter of a century in post-colonial times (1986-2010)}

A change in paradigm occurred around 1985, which can be symbolized by the development in 1984 of Demographic and Health Surveys (DHS) by IRD/ Macro institute. These were the years of new integrated programs such as the "Child Survival program", large scale programs aiming at reducing under-five mortality through various means. The focus was on a broader view of maternal and child health, with family planning being seen only as one element of population health, and above all on evaluation of interventions. Since considerable amount of money was spent on family planning programs and on health programs, governments and international agencies wanted to have precise information about the effects of these programs, and to know more about the context and other determinants of pop- 
ulation change.

The contribution of DHS surveys

The IRD / Macro institute, now renamed ICS / Macro, celebrated its $25^{\text {th }}$ anniversary recently, in 2009. It conducted five rounds of surveys of five years each, and started its sixth round, with a total of more than one-hundred surveys in sub-Saharan Africa. Over the years, the DHS surveys became more and more comprehensive, including not only demographic variables, but also lots of contextual variables on perception, attitudes and behaviours, anthropometric measures for adults and children, and more recently biomarkers focusing on infectious diseases (HIV/ AIDS, malaria, syphilis, chlamydia), on nutritional status (Vitamin A, anaemia, iodine deficiency, zinc, lead poisoning), and on some chronic diseases (hypertension, diabetes, cholesterol). Beyond classic DHS surveys, special surveys were conducted on HIV (AIS surveys), on malaria (MIS surveys), on service provision (SPA surveys), and on various topics, including education, maternal mortality and causes of death. They now include systematically GPS coordinates of household clusters, allowing detailed mapping.

Within a few years, DHS surveys became the leading source of knowledge on demographic parameters and their determinants, as well as the main source of population based information on HIV/AIDS prevalence, malaria, and malnutrition. They are the basis of a huge amount of demographic and epidemiologic research. They allowed detailed mapping of HIV prevalence, and of specific health problems such as malnutrition and anaemia. In-depth research on these data is possible by the open-access policy to individual data, which led to very innovative research and new findings. Of course, they do have limitations: they are missing the marriage histories, which were available in WFS surveys, they do not provide life tables, and do not have information on causes of death, except in a few studies such as that of Ghana, 2007.

Much of what has been learned on the erratic patterns of the demographic and health transitions in Africa originates from DHS surveys. Extensive use of DHS surveys allows one to study changes in - and patterns of - mortality, fertility, nuptiality, adult and child anthropometry, HIV/AIDS, sexual behaviour, and even sex ratios at birth (Garenne \& Gakusi, 2004, 2006; Garenne \& Zwang, 2006, 2008; Garenne, 2008; Garenne, 20I la,b; Garenne 2002, 2004, 2008, 2009; Garenne et al., 2009). The DHS surveys could by themselves answer important questions, such as the demographic impact of male circumcision on HIV prevalence, found to be nil, or the impact of hormonal contraception on susceptibility to HIV (Garenne, 2006a,b \& 20I0; Leclerc \& Garenne, 2008a,b; Leclerc et al. 2008). These results are important since they measure directly a population impact, and so the DHS surveys appear more cost-effective than complex epidemiological studies such as clinical trials or case-control studies aiming at answering similar questions. DHS surveys also provide the key parameters for simulation exercises, such as those conducted on the HIV epidemics (Leclerc et al. 2009).

Other programs of sample surveys

Another program of demographic and 
health surveys covering sub-Saharan Africa is the Multiple Indicator Cluster Survey program (MICS) run by UNICEF. These surveys are much less detailed and of lower quality. They provide information on fertility, mortality and selected health indicators in countries lacking other information. Other countries had special series of national demographic surveys, such as the "October Household Surveys" in South Africa, numerous surveys on migration (Bocquier and Traoré, 2000; Zachariah and Condé, 1980), as well as a number of population based surveys on HIV seroprevalence. There are also many more small-scale surveys which have only a local scope, and which often are not known because they are not disseminated.

Demographic Surveillance Systems (DSS)

Another major development for demographic research over the past 25 years has been the development of Demographic Surveillance Systems (DSS) in many African countries (Das Gupta and Garenne, 1997). They are now grouped into the IN-Depth network, whose first meeting was in 200I. (see IN-Depth web site) The network includes some 17 demographic surveillance systems (DSS), also called sentinel demographic sites, in sub-Saharan Africa. They have been very influential in promoting indepth, high quality research, and comparative research, as exemplified by a series of comparative studies on mortality, fertility, migration, causes of death, and inequalities. (see IN-Depth web site)

Censuses and the contribution of the IPUMS project

The idea of gathering and making systematic use of the information in population censuses started with the ACAP project (see ACAP web site). Unfortunately, this project did not go very far, and the fact that the leaders did not share the data provided by national agencies hampered any further research. Fortunately, much census data is now archived by the IPUMS-international project, which provides open-access to individual data, harmonized and unharmonized (see IPUMS web site). This program offers a huge potential for research of population structures, household structures, migration, social composition, geographical patterns and urbanization. They also often include data on fertility, mortality and maternal mortality, which could make a huge contribution because of their large sample size. They seem particularly useful for studying maternal mortality, although they focus only on pregnancyrelated deaths and lack the information on obstetric deaths (Garenne et al. 2008, 20II).

The issue of vital registration

Vital registration remains poorly utilized in African demography, despite some positive experiences (François, 1988; Garenne \& Zanou, 1995). Among the negative experiences are many failed experiments throughout Africa. For instance Lorimer (1968) noted that vital registration started in Uganda in 1904, which has worked ever since, but remains very incomplete and still not usable a century later. A similar experience could be found in Ouagadougou, where completeness went down from 1960 to 1990, making it now useless. There are a few experiences of systems that main- 
tained a good coverage in large cities, such as Dakar in Senegal, Abidjan in Cote d'lvoire for adults, Brazzaville in Congo, Libreville in Gabon, which were used for estimating the impact of HIV/ AIDS (Garenne et al. 1995a,b; Pictet et al. 1998). One of the oldest and most successful examples of vital registration is that of Antananarivo in Madagascar, which started even before the colonial period, and has been maintained at high coverage ever since, allowing detailed mortality calculations by age, sex and cause of death (Garenne et al. 200I; Garenne 2007). In the past 25 years, one of the success stories has been South Africa, where vital registration was very weak before 1990 for the Black/African population, but became almost complete for adults by year 2005, allowing detailed demographic analysis. However, coverage for children still remains low in that country.

\section{Past and present of indirect methods}

Indirect methods were developed by William Brass, who was a statistician at the East-African Statistical Office at the end of the colonial period, when the first censuses were conducted. They were extended by himself and his students at Princeton University and at the Centre for Population Studies at the London School of Hygiene and Tropical Medicine over a period of some 25 years. The indirect methods aim at producing average estimates of past fertility and mortality using simple questions and calculations, which also allow occasionally for trend estimations. They are based on restrictive assumptions, which were probably roughly fulfilled in the 1950s and 1960s, but which are increasingly violated due to the erratic patterns of population changes in Africa. They have become less useful over the years, and the DHS surveys hardly use them, preferring more precise direct calculations, with proper point estimates and confidence intervals. A few examples of the limitations of indirect methods are given below.

a. The " $P / F$ ratio method" in situations of changing fertility levels. Cameroon underwent ups and downs in fertility trends, with estimated values of TFR of 5.7 in 1963, 7.0 in 1983 and 5.3 in 2003, the age pattern of fertility remaining similar over the years. The impact of these changes on $\mathrm{P} / \mathrm{F}$ ratios can be estimated assuming perfect data, by recalculating cohort fertility assuming regular period changes with a constant age pattern. In 1983, after a period of rising fertility, the P/F would be 1.18 at age 25-29, I.04 at 45-49 and below one before age 20. In 2003, after a period of declining fertility, the P/F ratio would be I.0 I at 25-29 but now I. I 5 at 45-49, all these differences being only due to violation of the hypothesis of constant fertility, and not to miscounting events. Note that this was already noted by the author of the original article in The Demography of Tropical Africa who stated on page 6I: "Unfortunately, the $P / F$ ratios are almost certainly affected by other factors than forgetting". Note that more than half the African countries experienced fluctuations in fertility trends, and all are now undergoing fertility decline, at least in urban areas.

b. The "Brass method" in situations of changing mortality. Mozambique underwent major changes in mortal- 
ity due to the severe impact of the civil war which raged between 1975 and 1992. For the country as a whole, the under-five death rate declined from about 400 per 1000 in 1960 to 208 per 1000 in 1980, rose to 25I per 1000 in 1991, and declined to 134 per 1000 in 2003. Mortality changes were even more dramatic in the central part of the country, the most affected by the civil war. In this type of situation, Brass estimates would simply smooth out all the changes, and lead to very inaccurate results for the critical years. (Garenne et al. 1996) This type of situation is not unique, since more than half of African countries went through phases of decreasing and increasing mortality, the most recent example being countries highly affected by HIV/ AIDS. Another shortcoming of the Brass method is the use of age of mother as a main criterion for stratification, since age of mother is in itself a risk factor of child mortality. In particular, the inclusion of the 1519 age group is misleading for readers not aware of this bias. This is a recurrent problem in figures produced by MICS surveys, which show systemically increasing mortality for the most recent period, corresponding to the 15-19 age group. (see UNICEF web site)

c. Adult mortality. Some of the indirect estimates allow one to compute the mortality of young adults from questions on survival of parents or brothers and sisters. Here again, severe violation of hypotheses, and in particular the correlation between the survivorship of persons belonging to the same family, seriously biases the estimates. This has been recognized for a long time, and for instance was found in the Agincourt study in South Africa. (Garenne et al., 1997)

d. Completeness of death registration. Brass and others have developed techniques for estimating completeness of death registration. These are based on numerous assumptions. Here again, when violated, they may lead to inconsistent results. For instance, estimates made from the 200 I census in South Africa suggest an under-count of $45 \%$, which would imply implausibly high level of mortality, and would imply to increase fertility to abnormally high levels to match the observed population growth. (Hill et al., 2007)

e. Sisterhood method. Last, an indirect method allows one to compute estimates of maternal mortality from questions on survival of sisters. The overall idea may look great, but the outcome may lead to senseless results. Firstly, counting as maternal death any death during the maternal risk period (pregnancy, delivery, post-partum), whatever the cause, produces non-specific results, since this mixes obstetric deaths with deaths that are unrelated with the pregnancy and with fortuitous deaths. Secondly, and as for the Brass method, the sisterhood method does not provide a proper point estimate, but rather a weighted average of estimates over the years preceding the survey. Thirdly, it does not provide proper confidence intervals, which are far from trivial. This is in fact the worse scenario for estimating progress in 
safe motherhood. The opposite is needed: a specific case definition, precise point estimates, and proper confidence intervals. (Garenne and Friedberg, 1997; Garenne, 20II)

\section{Discussion: current challenges}

\section{Measurement}

The measurement issue, which was the core of demographic research more than 25 years ago, is no longer a serious problem for demographers. Most issues of data quality have been sorted out, and we have the tools to conduct precise interview surveys. In Africa, age, missing values and inconsistent answers are still problematic, but affect only a small proportion of questionnaires when surveys are well conducted. (Pullum 2006, 2008) These minor errors do not affect levels and trends in demographic indicators, nor do they affect the effects of explanatory variables in multivariate analysis. Furthermore, proper procedures of imputation for missing values may allow to compensate for the inaccuracy. One of the recurrent problems using survey data is the calculation of confidence intervals for point estimates, which is not always done in demographic analysis, although statistical methods and software are widely available. Furthermore, the issue of estimating trends from retrospective sample survey data still remains, although many options are available. (Garenne, 20ll) Of course, these issues do not apply to censuses, which have huge samples and small confidence intervals. With a few exceptions, African countries still lack life tables at national level, and even more at sub-national level, at least for urban and rural areas. This is primarily due to the fact that data on deaths in past 12 months have not been systematically recorded in censuses, despite recommendations from the United Nations, and when it happened, this was often not carefully done. Of course, there is no reason why deaths in past 12 months could not be recorded properly by age and sex if appropriate questions were asked in a census and if great care was taken for age estimation.

\section{Demography and public health}

In the field of public health and epidemiology more work could be done to better understand the complex processes underway and their rapid changes. Here demographers can make a big contribution by bringing a population approach, which is very different from that of clinical epidemiology. This field requires typically multi-disciplinary research. A good example of what has been achieved is the research on HIV/ AIDS epidemiology and demographic impact, where demographers had to develop new tools and new surveys, and where they made a very significant contribution over the past 25 years (Newell et al., 2004; Marston et al., 2005). This is a typical example of a new problem, an emerging disease, which beyond demographic models required understanding of the epidemiology of sexually transmitted diseases, of sexual behaviour, of mortality, and of the cultural context of African societies and the numerous effects of economic development. Another issue, which remains under-researched, is the recent dynamics in the huge pockets of extreme poverty in the booming African cities. A good example is the research conducted by the APHRC (African Pop- 
ulation and Health Research Centre) in Nairobi since 1997 (see APHRC web site). More of those studies are needed to better document these new dynamics. Numerous health issues have emerged in recent years which obliged demographers to develop new approaches. These include the resurgence of tuberculosis, the emergence of resistant malaria followed by large scale efforts to malaria control, the ups and downs of cholera epidemics throughout the continent, the emergence of obesity, diabetes and hypertension among the wealthier strata of African populations, and the severe stress associated with rapid social change. More research is also needed on adolescents, beyond contraception and sexually transmitted diseases, from nutrition to stress and adaptation to fast changing social environments. All these issues deserve more research from demographers with a proper population approach.

Towards ecology and environmental studies

With rapid population growth since 1930 and its numerous consequences on the environment, in a context of globalization of national economies and of global warming, the next series of issues to be addressed by demographers will deal with the environment, and the population approach of ecological problems. For this doing, we will need new forms of training, and an adaptation to new types of issues, as happened 25 years ago when the focus shifted to public health.

Open-access to data and results

A key factor of the outstanding development of African demography over the past 25 years has been the new pol- icy of open-access to original individual data. In this respect the DHS project and the IPUMS project are the best examples of what can be achieved, and of the immense benefits of open-access. The few countries in Africa which refused to release their data have lost the richness of further analysis, and do not appear in many detailed international comparisons. They did not have any gain from their restrictive policy.

Likewise, the publication of findings made immense progresses over the past 25 years, as exemplified by this Journal: African Population Studies. The development of the internet simply changed the scale of intellectual exchanges. Finding a paper, even a working paper, is no longer the issue that it was 25 years ago. Here again open-access to scientific journals is very important for optimal dissemination of findings, and some initiatives, such as Bioline International (see web site), made an immense contribution for African researchers. Open-access and rapid dissemination also narrowed the gap between scientists and decision makers, and made the results of the research more useful for the whole community.

This paper covers a series of classic issues. Of course, there are many other issues which were not addressed, which will be dealt with in other parts of this collection. To list a few: the huge migration flows and changes in the labour force participation that are occurring in Africa and their relationships with economic development, globalization, changing laws and rules of the game which have been so rapid in the past 25 years, with numerous dramatic consequences. Needless to say 
that there is a huge amount of work to be done for the coming generations.

\section{References}

Bado, J.P. 2005. Conquêtes médicales: histoire de la médecine moderne et des maladies en Afrique. Karthala, Paris.

Bocquier, P. and Traoré, S. 2000. Urbanisation et dynamique migratoire en Afrique de l'Ouest. La croissance urbaine en panne. In Decaluwé, B., JC. Dumont, S. Mesplé-Somps, V. Robichaud. (eds). Union économique et mobilité des facteurs: le cas de l'UEMOA. Paris, L'Harmattan.

Brass, W., Coale, A.J., Demeny, P., Heisel, D.F., Lorimer, F., Romaniuk, A., van de Walle, E. 1968. The demography of tropical Africa. Princeton University Press.

Cantrelle, P. 1969. Étude démographique dans la région du Sine-Saloum : état civil et observation démographique. Paris, ORSTOM, I2I p. (Travaux et Documents, no I).

Cantrelle, P., and Leridon, H. 197I. Breast-feeding mortality in childhood and fertility in a Rural Zone of Senegal. Population Studies, 25(3) : 505-533.

Cantrelle, P. (1 974). Population in African development. Ordina edition, Liège, Belgium.

Caldwell, J.C., and Okonjo. 1968. La population de l'Afrique tropicale. Population Council, New York.

Clairin, R., Condé, J., Fleury-Brousse, M., Waltisperger, D., Wunsch, G. 1980. La mortalité dans les pays en développement. Nouvelles tables type de mortalité à l'usage des pays en développement. Paris, Centre de Développement de l'OCDE.
Cordell, D.D. and Gregory, J.W. 1980. Historical demography and demographic history in Africa: theoretical and methodological consideration. Canadian Journal of African Studies; |4(3): 389-4 I6.

Das Gupta, M., and Garenne, M. (editors). 1997. Prospective community studies in developing countries. Oxford (UK), Oxford University Press.

El-Badry, M.A. 196I. Failure of enumerators to make entries of zero errors in recording childless cases in population censuses. JASA, 69(): 909-924.

Feachem, R.G., Jamison, D.T. (eds). 1991. Disease and mortality in subSaharan Africa. World Bank and Oxford University Press, New York.

François, M. 1988. L'état civil, in : Clairin et al., De l'homme au chiffre. Réflexions sur l'observation démographique en Afrique, p. 9l-I 12. - Paris, CEPED, 329 p. (Etude du CEPED, no I)

Galeoti, G., (196I), Problemi demografici dei paesi sottosviluppati e solidarieta internazionale. G. Malipiero, Bologna, Italy.

Garenne, M. 1982. Problems in applying the Brass method in Tropical Africa: a case study in rural Senegal. Genus. 38 (I-2) : I 19-1 34.

Garenne, M. 1985. Do women forget their Births? A study of birth histories in rural Senegal. United Nations Population Bulletin, 1994, 36 : 43-54.

Garenne, M. and O. Fontaine. 1986. Assessing probable causes of deaths using a standardized questionnaire. A study in rural Senegal. In: Vallin, J., D'Souza S., and Palloni, A. (ed). Measurement and analysis of mortality. Proceedings of the IUSSP seminar held in Sienna, 7-10 July, 1986. 
Clarendon Press, Oxford: |23-|42.

Garenne, M., Maire, B., Fontaine, O., Dieng, K., Briend, A. 2000. Risques de décès associés à différents états nutritionnels chez l'enfant d'âge préscolaire. Etudes du CEPED n $\mathrm{n}^{\circ} \mathrm{7}$, $192 \mathrm{p}$.

Garenne, M., Cantrelle, P. 1989. Prospective Studies of Communities: their unique potential for studying the Health Transition. Reflections from the ORSTOM experience in Senegal. In: Cleland, J, and Hill, A., (ed.). The Health Transition: Methods and Measures. Proceedings of an International Workshop, London 7-9 June, 1989. pp 25I-258.

Garenne, M., Leroy, O., Beau, J.P., Sene, I. 199I. Child mortality after high-titre measles vaccines: prospective study in Senegal. The Lancet, Oct I2, 1991; 338 ii (8772): 903-907.

Garenne, M., and Cantrelle, P. 199I. Three decades of research on population and health: the ORSTOM experience in rural Senegal: 19621991. In:. Das Gupta, M., and Garenne, M. (eds). Prospective community studies in developing countries. Oxford (UK), Oxford University Press (1997): 233-252.

Garenne, M. 1998. Potentiel et limites des observatoires démographiques. In : Clignet, R. (ed). Observatoires du développement, observatoires pour le développement. Paris, éditions de I'ORSTOM (1998), pp. I59-I 72.

Garenne, M., Madison, M., Tarantola, D., Zanou, B., Aka, J., Dogoré, R. 1995. The demographic impact of HIV/AIDS in West Africa. Volume I : Abidjan. (a report to USAID / REDSO). Harvard School of Public Health, François-Xavier Bagnoud
Center for Health and Human Rights. Working Paper Series No 4, June 1995. $190 \mathrm{p}$.

Garenne, M., Madison, M., Tarantola, D., Testa, J., Mboup, S., Wade, A., Hane, A. 1995. The demographic impact of HIV/AIDS in West Africa. Volume II : Dakar and Ouagadougou. (a report to USAID / REDSO). Harvard School of Public Health, François-Xavier Bagnoud Center for Health and Human Rights. Working Paper Series No 5, August 1995. 183 p.

Garenne, M., Zanou, B. 1995. L'état civil en Afrique : que peut-on en tirer? In: Clins d'oeil de démographes à l'Afrique et à Michel François. Paris, Documents et Manuels du CEPED $n^{\circ} 2$ : 29-42.

Garenne, M., Friedberg, F. 1997. Accuracy of indirect estimates of maternal mortality : a simulation model. Studies in Family Planning, 28(2): I 32142.

Garenne, M., Coninx, R., Dupuy, C. 1996-b. Direct and indirect estimates of mortality change: a case study in Mozambique. In: Demographic evaluation of health programs, edited by Myriam Khlat. ( Proceedings of the CICRED seminar on evaluation, Paris 26-28 February 1996). Paris, CICRED-UNFPA-French Ministy of Cooperation, pp. 53-63.

Garenne, M., Waltisperger, D, Cantrelle, P, Ralijaona, O. 200I. Impact démographique d'une famine ignorée : Antananarivo: 1985-1987. Economie de Madagascar, 4 (Dec 1999): 247264.

Garenne, M. 2003. Sex differences in health indicators among children in African DHS surveys. Journal of Bio- 
social Sciences, 35(4):60I-6I4.

Garenne, M., Zwang, J. 2004. Social change and premarital fertility in Madagascar. Southern African Journal of Demography; 9(I):27-48.

Garenne, M. 2004. Age at marriage and modernization in sub-Saharan Africa. Southern African Journal of Demography; 9(2): 57-77.

Garenne, M. 2004. Sex ratios at birth in populations of Eastern and Southern Africa. Southern African Journal of Demography; 9(I):91-96.

Garenne, M., Gakusi, E. 2004 Reconstructing under-five mortality trends in Africa from demographic sample surveys. DHS Working Papers No 26. IRD-Macro.

Garenne, M., Zwang, J. 2006. Premarital fertility and ethnicity in Africa. DHS Comparative Reports No. 13. Calverton, Maryland, USA: Macro International Inc. 87 p.

Garenne, M. 2006. Male circumcision and HIV control in Africa. PLoS Medicine 3(I): e78. (Letter)

Garenne, M. 2008. Long-term population effect of male circumcision in generalized HIV epidemics in subSaharan Africa. African Journal of AIDS Research; 7(I): I-8.

Garenne, M. 2008. Fertility changes in sub-Saharan Africa. DHS Comparative Report, No 18. Calverton, Maryland, USA: Macro International Inc. $128 \mathrm{p}$.

Garenne, M. 2009. Situations of fertility stall in sub-Saharan Africa. African Population Studies; 23(2): 173- 188.

Garenne, M. 2008. Poisson variations of the sex ratio at birth in African demographic surveys. Human Biology; 80(5):473-482.

Garenne, M. 2009. Sex ratio at birth and family composition in sub-Saharan Africa: inter-couple variations. Journal of Biosocial Science; 4 I (3):399-407.

Garenne, M., Zwang, J. 2008. Premarital fertility and HIV/AIDS in Africa. African Journal of Reproductive Health; I2(I): 64-74.

Garenne, M., McCaa, R., Nacro, K. 2008. Maternal mortality in South Africa, 2001: from demographic census to epidemiological investigation. Population Health Metrics; 6(4): I - I 3

Garenne, M., Leclerc, P., Matthews, A. 2009. Parametrisation of the transition to first marriage with the Picrate model: Application to African countries using DHS surveys. Southern African Journal of Demography; I2(I): 109-12I.

Garenne, M., McCaa, R., Nacro, K. 2010. Maternal Mortality in South Africa: an update from the 2007 Community Survey. Journal of Population Research; 28(I):89-101.

Garenne, M. 20I I. Trends in nutritional status of adult women in sub-Saharan Africa DHS surveys. DHS Comparative Reports No 27.

Garenne, M. 20I I. Testing for fertility stalls in DHS surveys. Population Health Metrics, (forthcoming)

Garenne, M. 20 I I. Estimating obstetric mortality from pregnancy related deaths. Studies in Family Planning, (forthcoming)

Garenne, M. 20I I. The impact of HIV/ AIDS on the health transition among under-five children in Africa. In: Letamo, G. (ed): Social and psycholigical aspects of HIV/AIDS and their ramifications (Chapter 13), In-Tech Publishers, Rijeka, Croatia: 237- 
248.

Gendreau, F. 1977. La démographie des pays d'Afrique: revue de synthèse. Population, 1977(4-5): 899-943.

Gendreau, F. 1993. La population de l'Afrique. Manuel de démographie. Paris, Karthala.

Groupe de Démographie Africaine. 1971. Afrique Noire, Madagascar, Comores, Démographie Comparée. DGRST, Paris.

Hill, A. 199I. Infant and child mortality: levels, trends and data deficiencies. In: Feachem, R.G. and Jamison D.T. (eds), Disease and mortality in subSaharan Africa. World Bank and Oxford University Press, New York.

Hill, K., Queiros, B., Stanton, C., AbouZahr, C. 2007. Measuring maternal mortality through the population census: examples from Africa. Paper presented at the UAPS conference, Arusha, Tanzania.

Leclerc, P., Matthews, A., Garenne, M. 2009. Fitting the HIV/AIDS epidemic in Zambia: a two-sex micro-simulation model. PLoS One; 4(5): e5439.

Leclerc, P., Dubois-Colas, N., Garenne, M. (2008). Hormonal contraception and HIV prevalence in four African countries. Contraception; 77(5):37I376.

Lericollais, A. (ed). 1995. Les paysans Sereer (Sénégal) : permanences et changements. Paris, ORSTOM.

Lorimer, F. 196I. Demographic information on Tropical Africa. Boston University Press, $207 \mathrm{p}$.

Lorimer, F. 1968. Introduction. In: Brass, W., et al. (eds). The Demography of Tropical Africa. Princeton University Press, 3-II.

Marston, M., Zaba, B., Salomon, J.A., Brahmbhatt, H., Bagenda, D. 2005.
Estimating the net effect of HIV on child mortality in african populations affected by generalized HIV epidemics. J Acquir Immune Defic Syndr; 38:219-227.

Matthews, A., Leclerc, P., Garenne, M. 2009. The Picrate model for fitting the age pattern of first marriage. Mathématiques et Sciences Humaines; No 186 ; 47(2): 17-28.

Newell, M.L., Brahmbhatt, H., Ghys, P. 2004. Child mortality and HIV infection in Africa: a review. AIDS; 18: S27-S34.

Ominde, S.H. and Ejiogu, C.N. (eds). 1972. L'accroissement de la population et l'avenir économique de l'Afrique. Population Council, New York.

Pictet, G., Le Cœur, S., M'Pelé, P., Brouard, N., Lallemant, M. 1998. Contribution of AIDS to the general mortality in Central Africa: evidence from a morgue-based study in Brazzaville, Congo. AIDS; 12: 22172223.

Pullum, T.W. 2006. An assessment of age and date reporting in the DHS Surveys, 1985-2003. DHS Methodological Reports No 5, Macro International, Calverton, $93 \mathrm{p}$.

Pullum, T.W. 2008. An assessment of the quality of data on health and nutrition in the DHS Surveys, 19932003. DHS Methodological Reports No 6, Macro International, Calverton, $165 \mathrm{p}$.

Retel-Laurentin, A. 1974. Infécondité en Afrique Noire: Maladies et conséquences sociales, Masson, Paris.

Romaniuk, A. 1961.Tableau général de la démographie congolaise : Enquête démographique par sondage 1955-1957, République du Congo : Ministère du plan et de la coordination 
économique, Service des statistiques, Kinshasa, 214 p.

Shaul, J.R., Myburgh, C.A. 1950. Provisional results of the sample survey of the African population of Southern Rhodesia, 1948. Population Studies; 3(3): 274-285.

Tabutin, D. and Schoumaker, B. 2004. La démographie de l'Afrique au sud du Sahara des années 1950 aux années 2000, Synthèse des changements et bilan statistique. Population, 59(3-4): 52I-62I.

Tollman, S.M,, Kahn, K., Garenne, M., Gear, J.S.S. 1997. Reversal in mortality trends: evidence from the Agincourt field site, South Africa, 1992| 995. AIDS; I3(9): I09 I- 097.

Van de Walle, E., Pison, G., Sala-Diakanda, M. (eds). 1992. Mortality and society in sub-Saharan Africa. Oxford, Clarendon Press.

Van de Walle, E. (ed). 2005. African Households: Censuses and Sur- veys. Armonk: M.E. Sharpe.

Zachariah, K. C. and Condé, J. 1980. Migration in West Africa- Demographic Aspects. Oxford: Oxford University Press (A Joint World Bank-OECD Study).

Zwang, J., Garenne, M. 2008. Social context of premarital fertility in rural South-Africa. African Journal of Reproductive Health; I2(I): 97-109.

\section{Web sites}

APHRC: www.aphrc.org

Bioline International: http://www.bioline. org.br

DHS: www.measuredhs.com

In-Depth Network: www.indepth-network.org

IPUMS: www.international.ipums.org

Niakhar: http://www.ird.sn/activites/niak harl

UAPS / UEPA: http://www.uaps-uepa.org

UNICEF: http://www.unicef.org 


\section{Box 1: Challenges for future research in African demography}

Data collection and analysis

- Promote the development of vital registration, and the analysis of available data, even local data (e.g. cities).

- Make better use of censuses to assess mortality and fertility levels and trends.

- Construct national and sub-national life tables based on robust data (and not on models).

- Add causes of death whenever possible, including hospital based.

- Adhere to strict case definitions and reliable indicators to monitor trends and evaluate progresses towards MGDs.

Knowledge and theory

- Add contextual information to document demographic trends (e.g. economic development, creation of job opportunities, local dynamics, local situations, political choices, development programmes, etc.).

- Better separate the study of determinants of demographic trends (longitudinal) from that of factors of differentials in demographic indicators (cross-sectional).

- Develop new approaches and concepts to study the complex relationships between population and environment. 